tion and considers likely areas for profitable future research.

Most of the papers in this volume are informative, well presented, and adequately referenced, though much of the material is often a restatement or summary of work published elsewhere. For the reader not fully conversant with this field there are numerous interesting studies and several concise but valuable review articles, particularly those on laser photocoagulation for diabetic macular oedema and the management of choroidal neovascularisation and corneal neovascularisation.

This book will have particular appeal for ophthalmologists specialising in retinal diseases and also provide useful reading and background data for trainec ophthalmologists or basic scientists wishing to embark on investigative work on the ocular circulation and the many as yet unresolved facets of ocular neovascularisation.

DESMOND B ARCHER

A Colour Atlas of Allergy. By William F JaCKSON and Rino Cerio. Pp. 126. £35·00. Wolfe: London. 1988.

This book is the latest in the excellent Wolfe series of simple educational textbooks. Among the wide range of topics covered are basic mechanisms of allergy and investigation of allergic disorders in addition to allergic disorders of the skin, eye, nose, lungs, and gut, and allergic drug reactions. Some chapters describe 'allergy' as just type I hypersensitivity reactions and others incorporate all type I-type IV reactions, which is confusing for the amateur immunologist. Moreover, the inclusion of separate chapters on autoimmune diseases and immunodeficiency syndromes suggest that clinical immunology might have been a more appropriate title.

Professor Easty has contributed the chapter on eye disease. He naturally concentrates, and beautifully illustrates, anterior segment problems, including herpes simplex keratitis because of its increased incidence in atopic subjects.

The hallmark of the book (and the entire series) is the wealth of illustrations and the clarity of the information. After reading the chapter on skin prick tests I thought these were both easy to perform and interpret and perhaps even within the grasp of an ophthalmologist's clinical expertise.

The book includes extensive material covering many clinical specialties all linked by disordered immunity. It is difficult to know who it is aimed at, though undoubtedly all medical students, budding physicians, and curious ophthalmologists would find it both fun and informative.

\section{FI.IZABETH GRAHAM}

Optic Neuritis. Eds. R F Hess and G T Plant. Pp. 310. £35.00. Cambridge University Press: Cambridge. 1986.

The first accurate clinicopathological description of multiple sclerosis in this country came from the pen of a Guy's physician. Dr Moxon, in 1875, and nine years later an eminent St Thomas's ophthalmologist, Nettleship. described the first cases of optic neuritis. In the absence of the diagnostic techniques available today, the group of patients described was heterogeneous and included cases of ischaemic papillopathy and syphilis, but most of the patients definitely had optic neuritis, presumably duc to demyelinating disease. This volume celebrates the centenary of Nettleship's description and is the report of collected papers from a meeting held in November 1984.

The chapters lay great emphasis on the pathophysiology and testing of visual function in optic ncuritis, but with minimal consideration of the clinical assessment. Thus the opening chapter by Campbell emphasises the value of contrast sensitivity in normal and abnormal vision. There is an interesting chapter on pathogenesis (McDonald) and onc on the neurologist's view of optic neuritis (Herman). The importance of immunological investigation is emphasised (Compston), and this surely will ultimately provide us with an explanation of the cellular events. This is followed by several chapters on the experimental investigation of optic neuritis with psychophysical tests. The experiments on mice have also provided important information and the interesting finding that both fast and slow axonal conduction is accelerated in this condition (Ikeda).

Thus this book provides a useful collection of papers on the scientific investigation of optic neuritis. However, there is little to help an ophthalmologist in the clinic. There is no discussion of colour vision or visual ficld abnormalities. There is no mention of the great mimic of optic neuritis, the sphenoid sinus mucocele, and the section on granulomatous optic neuritis is weak. However, the book is worthy of perusal by the clinical ophthalmologist.

M D SANDERS

\section{Notes}

\section{European Ophthalmic Pathology Society}

The 28th Annual Mecting of the European Ophthalmic Pathology Society was held in Copenhagen (Holte), Denmark on 22-25 May 1989 at the invitation of the Organising Secretary, Professor O A Jensen, assisted by Professor J U Prause. Professor G K Klintworth, of Duke University, Durham U S A and the Verhoeff Society, was the honoured guest. Thirty-two ordinary members of the society also attended the meeting.

The following papers were presented at the scientific meeting: Primary hyperoxaluria (primary oxalosis). (G K Klintworth, U S A). Retinoblastoma in an 'old paticnt ( $\mathrm{K}$ Arnesen, Norway). Conjunctival epibulbar fibrous histiocytoma with orbital extension (E Balestrazzi. Italy). Malignant lymphoma of the brain with vitreous involvement (M Brihaye-van Geertruyden, Belgium). Epithelioma cuniculatum of the eyclid, caruncle and orbit (A Brini, France). Pigmented epiretinal membrane (J G Cunha-Vaz, Portugal). Darier's disease and retinitis pigmentosa (a new oculocutancous syndrome?) (B Daiker, Switzerland). Juvenile familial amaurotic idiocy (Spielmeyer-Vogt) (D de Wolff-Rouendaal, The Netherlands). Macular corneal dystrophy with photophobia (A Garner, $U$ K). 